\title{
Aluminum doping impact on morphology and sensing response of zinc oxide nanostructures
}

\author{
Onkar Singh ${ }^{1}$, Manmeet Pal Singh ${ }^{2}$, Ravi Chand Singh ${ }^{1}$ \\ ${ }^{1}$ Department of Physics, Guru Nanak Dev University, Amritsar-143005, Punjab, India \\ Corresponding author's email: garhikang@gmail.com \\ ${ }^{2}$ Department of Applied Sciences, Khalsa College of Engineering \& Technology, Amritsar-143001, \\ Punjab, India
}

\begin{abstract}
:
In this piece of work, we have synthesized pure and aluminum doped zinc oxide and then studied their sensing response towards ethanol. We adopted a chemical route to synthesize pure and aluminum doped $\mathrm{ZnO}$, in this work we added different concentrations of aluminum by weight (1\% to $4 \%$ by percentage weight). The XRD studies revealed that synthesized materials are having wurtzite hexagonal crystalline structures. With the addition of dopant the crystallinity of the structures has decreased. FESEM images have clearly shown the modification of morphology of material with the addition of the dopant. With the addition of dopant sensing responses also have changed significantly.
\end{abstract}

Key words: Zinc Oxide; nanomaterials; doping; chemical synthesis; gas sensors

\begin{abstract}
Introduction
Volatile organic compounds are the primary sources of indoor environmental pollutants and are considered seriously harmful to the human. Therefore, work is required concerning the vapour detection and its development. In the past few decades, gas sensors have been one of the key areas of interest. Semiconducting metal oxide based gas sensors are one of the most extensively studied groups of gas sensors. For observable reasons n-type semiconductor gas sensors such as $\mathrm{SnO}_{2}$ and $\mathrm{ZnO}$ have attracted the attention of many users and scientists [1,2]. For continuous use, the sensors should exhibit a high reliability, sensitivity, and stability.
\end{abstract}

It is well known fact that gas-sensing properties of semiconducting oxide gas sensors can be modified by choosing an appropriate dopant $[3,4]$.

Sensing, dominantly being a surface involved phenomenon, the particles on the surface and more importantly their morphology and size play a crucial role in the sensing mechanism. In the recent years with the advent of nanostructured materials, the study on gas sensors has gained an impetus [5]. The enhanced surface activity is attributed to the surface-to-bulk ratio for the nano sized materials, which is much greater than that for coarse materials because large fractions of atoms are present at the surface due to which the surface properties become dominant.

In this work, we are reporting synthesis and sensing response of pure and aluminum doped zinc oxide.

\section{Experimental details}

\section{(i) Synthesis and doping of nanostructured $\mathrm{ZnO}$}

We started with a $0.2 \mathrm{M}$ solution of $\mathrm{ZnCl}_{2}$ prepared in distilled water, in this solution aluminum nitrate was added in different concentration such as $1,2,3$ and $4 \%$ by weight. Then resulting solutions were precipitated by adding an ammonium hydroxide drop wise at room temperature. The precipitates thus obtained were separated from rest of the liquids by filtering and were dried into powder at $120^{\circ} \mathrm{C}$. Then the powders were sintered at temperature of $500^{\circ} \mathrm{C}$ for three hours.

The crystal structure of the materials produced was characterized by powder X-ray diffraction (XRD) using $\mathrm{Cu} \mathrm{Ka}$ radiation with Shimadzu 700 Diffractometer system. Morphologies of the materials were analyzed from FESEM FEI Quanta 200F. 


\section{(ii) Fabrication of sensors and their testing}

The synthesized powder samples were processed into water based pastes. The paste was coated onto an alumina substrate $(12 \mathrm{~mm} \times$ $5 \mathrm{mmsize}$ ) between gold electrical contacts ( $2 \mathrm{~mm}$ apart) to obtain a thick film ( $20 \mu \mathrm{m}$ thickness). These samples were sintered at $350^{\circ} \mathrm{C}$ for $30 \mathrm{~min}$ to give them final shape ready for sensing.

The sensing characteristics of $\mathrm{ZnO}$ sensors were obtained with a home built apparatus consisting of a simple potentiometric arrangement and a test chamber of known volume in which a sample holder, a small temperature controlled oven and a mixing fan were installed. The fabricated sensor was placed in the oven kept at suitable temperature and a measured quantity of test gas ethanol was injected into the test chamber. The variation of voltage signal across a resistance connected in series with sensor was monitored and recorded with a Keithley KUSB -3100 data acquisition card.

Same procedure was repeated for different test gases sensing with all the samples at temperatures from 200 to $450^{\circ} \mathrm{C}$. Vapour sensing response of the sensor was determined as the $G / G_{0}$, where $G_{0}$ is the conductance of thick film sensor in an air ambience and $G$ is the conductance in a mixture of air and ethanol vapour.

\section{Results and discussion}

Figure 1 represents $X$-ray diffraction plots for pure $\mathrm{ZnO}$ and doped $\mathrm{ZnO}$ with different weight percentage of Aluminum. From the peaks we can clearly note down the wurtzite hexagonal geometry of the synthesized powders. Another significant observation from Fig. 1 the crystallinity of $\mathrm{ZnO}$ film was deteriorated with increasing $\mathrm{Al}$ content and no extra phases involving aluminum compounds were observed. Moreover, the peak intensities of those films decrease with increasing Al content, similar results were also observed by Caglar et al [6] for thin films.

Figure 2 represent FESEM of pure $\mathrm{ZnO}$ and $\mathrm{ZnO}$ with doping of different concentrations of $\mathrm{Al}$ by weight. These images clearly show modification in the morphology of $\mathrm{ZnO}$ due to doping of $\mathrm{Al}$. Fig 2(a) shows that pure $\mathrm{ZnO}$ is having well defined rod type morphology. With the increase in the concentration of the dopant $\mathrm{ZnO}$ has lost its morphology and rods are no longer prominent in the powder (Fig 2(b) - (e)).

Figure 3 represents the sensing response of pure and Al doped $\mathrm{ZnO}$ thick films for $250 \mathrm{ppm}$ ethanol at optimum operable temperatures. It

can be seen in the figure that response has increased with the addition of dopant.

Another important point that is apparent from the figure is that with the increase in the concentration of the dopant (from $1 \%$ by wt. to $4 \%$ ) sensitivity towards ethanol has reduced.

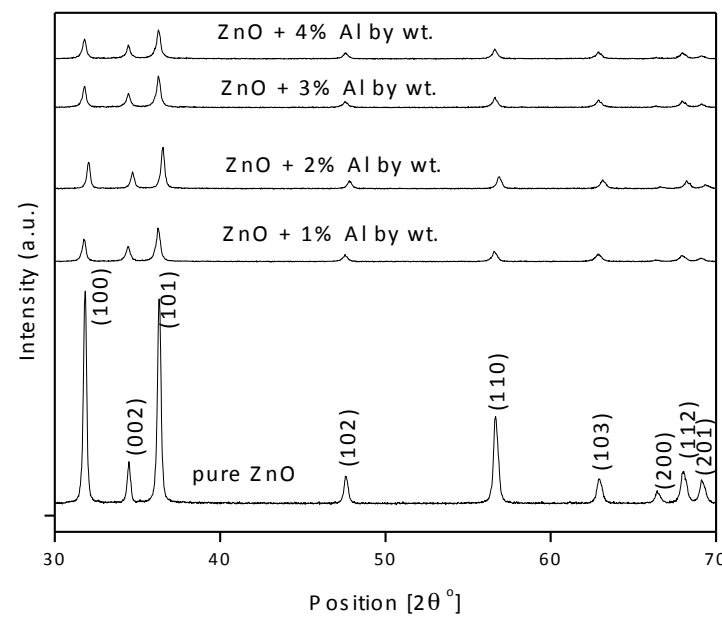

Fig. 1 XRD plot of pure $\mathrm{ZnO}$ and doped $\mathrm{ZnO}$ with different \%age of Al by wt.

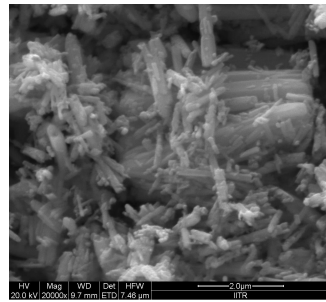

(a)

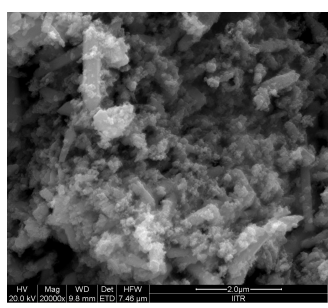

(c)

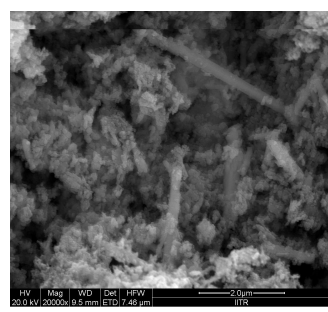

(e)

Fig. 2 FESEM images (a) Pure ZnO, (b) ZnO: 1\% Al (c) $\mathrm{ZnO}: 2 \% \mathrm{Al}$ (d) $\mathrm{ZnO}: 3 \% \mathrm{Al}$ (e) $\mathrm{ZnO}: 4 \% \mathrm{Al}$ 


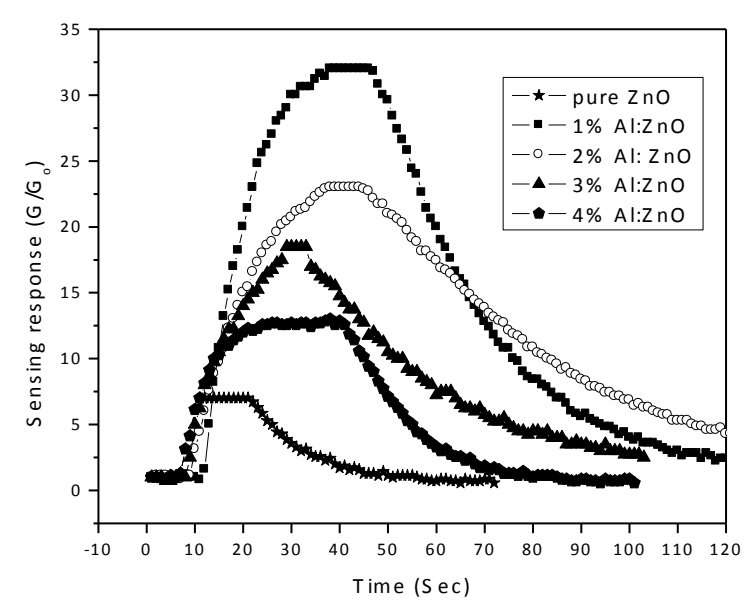

Fig.3. Sensing response of pure and Aluminum doped Zinc Oxide towards $250 \mathrm{ppm}$ of ethanol at various operating temperatures.

\section{Conclusions}

In this work, we were successful in modifying the morphology of the $\mathrm{ZnO}$ with the addition of different concentrations of aluminum by weight as a dopant. As sensing response is the surface phenomenon, so sensing behaviour was expected to change. With the addition of the dopant sensing responses towards ethanol have enhanced significantly.

\section{Acknowledgements}

Authors would like to thank following: University Grants Commission, New Delhi, India for financial support; IIT Roorkee for FESEM investigations. One of the authors Onkar Singh thanks CSIR, New Delhi for senior research fellowship.

\section{References}

[1] T. Krishnakumar, R. Jayaprakash, N. Pinna, N. Donato, A. Bonavita, G. Micali, G. Neri, Sensors and Actuators B 143, 198-204 (2009); doi: 10.1016/j.snb.2009.09.039

[2] H. Gong, Y. J. Wang, S. C. Teo, L. Huang, Sensors and Actuators B 54, 232-235 (1999); doi: 10.1016/S0925-4005(99)00119-7

[3] F. Paraguay D., M. Miki-Yoshida, J. Moralesb, J. Solis, W. Estrada L., Thin Solid Films 373, 137140 (2000); doi: 10.1016/S0040-6090(00)011202

[4] S. C. Navale, I.S. Mulla, Material Science and Engineering C 29, 1317-1320 (2009); doi: 10.1016/j.msec.2008.09.050

[5] A. Rothschild Y. Komem, Journal of Applied Physics 95, 6374-6380 (2004); doi: $10.1063 / 1.1728314$

[6] Y. Caglar, M. Caglar, S. Ilican, Current Applied Physics 12, 963-968 (2012); doi:10.1016/ j.cap.2011.12.017 